\title{
The Movement to a New Understanding: A Life-World-Based Study about How People Learn to Live with Long-Term Illness
}

\author{
Mia Berglund* and Susanne Källerwald \\ School of Life Sciences, University of Skövde, Skövde, Sweden
}

\begin{abstract}
Objective: The objective of the present study was to analyze and describe the phenomenon of learning to live with long-term illness.

Method: The design and implementation of the research was based on a reflective lifeworld approach. The study consisted of interviews with people who live with different types of long-term illness.

Results: Learning to live with a long-term illness happens in such a way as to respond to the will to live everyday life. The essential meaning of learning to live with long-term illness is constituted by the following elements: learning to know and live with a stranger, the driving forces of learning, learning methods are a balancing act, making the illness visible, as well as seeking knowledge and understanding. The result of the learning process can be understood as movement to a new understanding that is shown in the way the person with the illness acts and gives herself with the
\end{abstract} illness more space in life.

Conclusion: The results show that genuine learning is something that differs from learning information and that the learning must be supported by the sufferer's situation for a long period of time at an existential level.

\section{Introduction}

Patient experiences of living with long-term-illness have been described in several studies $[1,2]$. Suffering from such an illness is a life-changing process [3] and generates a need to learn. This article highlights the learning process of individuals suffering from long-term illness. A major starting point for this study is that patients' learning has not previously been focussed on and, consequently, has not formed the basis for the creation of study programs and other forms of health services-teaching material. Previous research shows that the starting point for patient education often was a bio-medical or the so-called external perspective on illness [4]. This has been shown in research where the effects of patient education have been studied in the form of measureable values [5]. One consequence of this approach is that patients who do not follow the advice they receive are considered as noncompliant [6]. In previous research, an imminent risk also emerged that patients were excluded from participation in the care and treatment in their own health process [4,7]. Thus, a number of factors from the life-world approach are problematical and create difficulties for patients learning to live with a long-term illness [8]. Far too little attention has been given to the individual living with a long-term illness and whose experiences should be considered valuable and importantexperiences that, if utilized, can constitute a foundation for formulating a teaching material. A significant part of research in the educational/ didactic field has taken place in disciplines other than the caring sciences, for example, sociology [9] and psychology [10]. The theories and programs that underpin patient education are most often based on theories from outside of the caring sciences; in particular, a lifeworld didactic perspective is missing [6,8]. Thus, the motives exist for carrying out research of the learning process inpatients from a caring science perspective based on the life-world approach.

\section{Methods}

\section{Scientific approach and method}

The ontological and epistemological suppositions in this article are based on life-world theory [11-13]. In life-world theory, a person is seen as a lived body [13]. The lived body is simultaneously physical, mental, and existential. A person is a provider and a seeker of knowledge when she wants to take care of, comprehend, and understand life [11]. When a person suffers from long-term illness, the body is changed, and thus her access to the world is changed as well. The experiences of people living with long-term illness are seen in this research as constituting a possibility for learning, while learning is seen as a complex phenomenon that involves the whole person.

Dahlberg et al. [14] developed a research approach, termed Reflective Life-world Research (RLR), which is based on Giorgi's [15] phenomenological approach. The overall aim of the reflective life-world approach is to describe and clarify lived experiences in such a way that a person's knowledge and understanding of her existence and experiences is increased. The focus in this study was the experiences of people/ individuals with long-term illness. What does learning entail when living with long-term illness? What does learning contain? How does the learning process occur? What is the result of the learning process?

\section{Interview}

Qualitative interviews are described by Dahlberg et al. [16] as being a dialogue whose aim is to get the informant to reflect on her experiences. The reflective process is initialized by the use of questions [16], which lead to new thoughts. The questions are based on what is said in the interview, and their purpose is to direct attention towards the phenomenon and gain a greater understanding of its meanings. The interview in the present study is seen as a dialogue, in which the aim is to achieve openness and flexibility. The informant's attention has been directed towards the phenomenon, and the reflective process was encouraged with the use of more profound questions.

*Corresponding author: Mia Berglund, School of Life Sciences, University of Skövde, Skövde, Sweden, E-mail: mia.berglund@his.se

Received December 07, 2012; Accepted December 26, 2012; Published December 31, 2012

Citation: Berglund M, Källerwald S (2012) The Movement to a New Understanding A Life-World-Based Study about How People Learn to Live with Long-Term Illness. J Nurs Care 1:125. doi:10.4172/2167-1168.1000125

Copyright: () 2012 Berglund M. This is an open-access article distributed unde the terms of the Creative Commons Attribution License, which permits unrestricted use, distribution, and reproduction in any medium, provided the original author and source are credited. 


\section{Analysis in accordance with the reflective life-world approach}

The approach can be described as a dialectic process, starting with the whole, analysing its parts followed by the synthetic reconstitution of the whole with the aim to reach an understanding of the essence of the phenomenon $[14,16]$. The analysis starts with the initial whole, where the researcher acquaints herself with the text. Subsequently the focus of the reading is directed to the parts, which means seeking units of meaning: a word, a sentence, or a longer piece of text. The meanings are unpacked in this part of the process, and each meaning is reflected against the background of the whole. The next phase involves the building of clusters, which are the same as groups of meanings. When all the units of meaning in the data have been utilized and clustered into groups, it is time to move on to the next phase, the forming of the essence. Dahlberg et al. [14] describes the essence text as an abstraction and synthesis of the structure of meanings that makes the phenomenon into the actual phenomenon and nothing else. The essence can thus be understood as a new whole.

\section{Participants}

The study's participants had different long-term illnesses. The common denominator of these illnesses was that they affected the participants' daily lives. The informants themselves named their illnesses. The following illnesses and functional impairments were described (numerals in parentheses are used to indicate that two informants had the same illness or functional impairment): Rheumatoid Arthritis (RA), Bechterew's Disease, Chronic Obstructive Pulmonary Disease (COPD), varicose ulcer [2], heart attack [2], cardiac insufficiency [2], thigh-bone amputation without prosthesis, double lower leg amputation with two prostheses, hip arthritis [2] Multiple Sclerosis (MS) [2], diabetes, type 1 [2], renal failure [2], blindness, impaired vision [2], neuropathy [2], gastric paresis [2], sub-cortical white-matter dementia, Binswanger's disease (blood vessel abnormality), back pain, and alcoholism.

The ages of the participants varied between 21 and 84 . Five men and four women participated in the study. The participants were from four different municipalities in western Sweden. The interviews lasted between 35 and 117 minutes (with a mean of 60 minutes). The interviews were conducted in conjunction with dissertation work [8].

\section{Ethical considerations}

The ethical considerations for this study have been based on ethical principles of research $[17,18]$ and laws $[19]$ in Sweden at the time for data collection (September 2007-January 2008). Based on the ethical principles, the requirements of information consent, confidentiality, and use have been applied. All participants received a letter where he or she was invited to participate in the study. The participants were guaranteed confidentiality and were informed that participation was voluntary. After the participant had given their informed (oral and written) consent the interview was conducted. In the interview situation the researchers strove to remain open and flexible to the informants needs. It is a delicate task to get the informant to divulge more about their experience of this phenomenon without submitting him or her to pressure. The informants were all very grateful for the dialogue and they afterwards said that they had a good conversation and that they learned some things about themselves. Professional support was available if needed.

\section{Findings}

The essential meaning of learning to live with long-term illness concerns movement towards a changed understanding of access to the world. In this movement, in which everyday life as well as relationships with oneself and others is affected, a continual renegotiation is needed. Learning includes developing an understanding of the relationship between the demands of life and those of the illness. Learning happens as a response to the will to live an ordinary life. In order to be able to push the illness away in favour of the patient's pre-illness life, a learning process is needed where the sufferer paradoxically allows the illness more space. To learn to balance on life's tightrope is hard work that necessitates profound self-reflection. The self-reflection constitutes the instrument of learning and the learning process can be both hampered and supported by other people. Learning entails that the individual develops a new understanding of herself. The essential meaning of learning to live with long-term illness is constituted by the following elements of meaning;

- Learning to know and live with a stranger

- The driving forces of learning

- Learning methods are a balancing act

- Making the illness visible

- Seeking knowledge and understanding

- Care that impedes learning

- The result of learning

\section{Learning to know and live with a stranger}

The stranger is to be understood as the illness and the changed body. Learning involves getting to know the stranger, understanding how it affects the body, and learning to handle the changed life and constantly occurring problems.

When the stranger enters the person's life, the person does not want to let it in, which is done by refusing to acknowledge the stranger's existence. One way is by not naming the illness. One woman says that it took her 24 years before she pronounced the name of her illness. The fact that it is hard to let the stranger into one's life is shown through people finding other causes for their symptoms, causes which feel more familiar to their individual life-worlds.

Yes, it was that I refused to admit that I had rheumatoid arthritis. [...] I do not know; I was not sick. Sometimes when it was too hard, then I wrapped it with an elastic bandage and then people asked: 'What have you done? It's dislocated', I replied. And when my brother called, he always asked, 'Hello, how is it with the things that you do not have?' No, I did not want to talk about it; I did not want to admit it.

The stranger causes problems for those trying to live their familiar life. The stranger and the problems it imposes mean that the person does not recognize herself in her own body and must learn to access the world in new ways; the process is also about dealing with the fear of an uncertain future. This problem is expressed as follows by a person who is blind:

When you cannot see, then you lose companionship with people. You cannot go out as you want. You are limited pretty much to the home. One cannot decide that tomorrow I'm doing this, because it depends on how I feel.

The problems that the stranger causes in life mean that people do not feel at home in their living situation, which is expressed in selfdoubt and doubts about their capability.

\section{The driving forces of learning}

Learning to live with long-term illness can be characterized by the 
pursuit of a familiar life. This endeavour emerges as a key driving force towards learning as demonstrated by the desire, tenacity, and ability to influence one`s own health processes.

The will is a force that triggers learning and thus constitutes the engine of learning. This engine, in addition to the pursuit of the familiar life, is fuelled by the idea of maintaining independence. Refusing to be more sick, along with the desire to slow the deterioration, are the driving forces of the learning process, as a man with dementia says:

No, I did not want to accept that I would sit and not remember anything. It was difficult for me. Therefore, I had to learn to do little thingsto maintain my memory.

Obstinacy allows for the continuation of an active life during longterm illness. The person learns new strategies in order to be active. 'Yes, for the obstinacy I have, it's not of this world. But perhaps that is what makes you go forward'. Obstinacy is an engine for learning, but at the same time it can be a problem for realizing the limitations the illness actually has. 'Yes, it's clear that this has been a force helping me to succeed in life; yes, obstinacy in the right amount is good but not as much as I have. One dimension of obstinacy is that it promotes the perseverance and courage required in situations where learners understand how to use their bodies in a whole new way, for example, learning to walk with prostheses.

The ability to influence the health process is a force for learning. This is demonstrated as the individual has a possibility to influence restrictions in life and damage to the body. This drive is described by someone who will soon be in need of dialysis: 'It is only now when they wanted to put me in dialysis that I began to change my diet'. That these changes made an impact on this person's health is evidenced by his strengthened desire to learn more in order to further improve her health. The feeling of gain makes it easier to sustain changes and not revert to old habits.

\section{Learning methods are a balancing act}

Learning to live with long-term illness can also be described as an act of balancing, where the person learns to balance between the demands of both life and illness. To find a decent existence, one must weigh the pros and cons. The balancing act is about developing an understanding of life with the illness while highlighting the positive parts of life.

Yes, the illness itself makes life look like a downhill battle. I have diabetes and have to live with it. Interviewer: What do you do when that feeling comes? Yes, I might think about it a little bit, and then I think of somethingthat is positive in my life. My family.

Living as normally as possible while observing what causes the problems requires knowledge. A decreased energy level constitutes a lesson in itself, compelling the individual to consider which may lead to new insights: 'To learn where the limits are, how much you manage and how much you dare'. By observing physical reactions in different situations, those who are learning understand more about both themselves and the illness and thereby may gain a greater understanding of what causes certain reactions. Adding observations like pieces of a puzzle allows one to reach an understanding of the importance of balancing life with illness.

Hope is balanced against realistic expectations. The balancing act is about not giving up hope and at the same time not putting too much faith in it. 'One would of course like to feel healthy but I know that I cannot'.

\section{Making the illness visible}

In order for learning to take place, it is important to direct attention to the illness and allow it to become visible. This visibility is enabled by ability to express the thoughts and experiences of the illness in words. This includes being honest and open both to oneself and others. The visibility of experiences creates opportunities for reflection on one's own learning.

Being honest and open about the illness is described as an active choice that becomes part of the learning process. A man describes how he has previously found it difficult to talk about his illness, but that he 'now is more open [...].when I meet a new person, I usually say that I have diabetes, so they know it. If others have knowledge of the problem, it is easier to allow the illness and treatment to take place. 'I believe that if I am not honest and open about it, then I'm almost there again, so then I might as well be honest and open'.

\section{Seeking knowledge and understanding}

Learning to live with long-term illness is a process of seeking knowledge and understanding to manage the situation. Knowledge is applied when coming to terms with several illnesses simultaneously and increasing one understands of a threatening future. Sometimes, caregivers seem to hinder the patient's learning process.

The need for information is described in different ways, ranging from not wanting to know more to having a great need for more knowledge. A search for knowledge involves seeking a manifold image of the future at a time when the illness pictured by the general public, the media, and loved ones often is dark and frightening. This picture does not always correspond with one's own experiences. In this way, thoughts and discrepancies initiate the search for information.

The information given by professionals can be difficult to understand, especially in relation to one's own situation. '... No, it was not me .... If the professional does not offer the help that is needed; or, when the advice does not match patients' experiences, patients seek information on their own. When asked what information a man with MS had received from health care providers, he said 'Nothing at all, about what it was and what I should do so that it will not get any worse, and so I know nothing more than that I probably will be sitting in a wheelchair in the future'. This man received information about the illness from friends, relatives, and television. 'Yes, on House [TV series]'. This lack of information and ability to see the patient's needs cost patients uneasiness, anxiety and an inability to take charge of, and gain from, the improvements that the patient can achieve for his or her own benefit.

\section{Care that impedes learning}

Learning is impeded when caregivers do not see the patient as a person and do not believe what the patient says or see the patients fear.

The ability to understand and cooperate with doctors and nurses are hampered when professionals do not speak a language the patient understands: 'Yes, they say, those strange damn words that I don't have a clue what they mean'. Learning becomes more difficult when the patient is not allowed to ask questions:

I was terribly disappointed and I wanted to ask some questions and then he looked at me and said, here I am the one asking the questions.

The professionals impede patients' learning when they do not see their fear. Fear contributes to the patient's inclination to evade from both disease and health care. Fear is an obstacle for asking for and 
receiving help. The patient's fear is covered in the healthcare context. One informant said: 'No, I tried to look happy while I was at the hospital, but I was afraid and I didn't ask any questions because I was anxious to get away'. No one had asked him if he was afraid.

Doubts about the caregivers' knowledge and skills lead to a search for an alternative trustworthy explanation or the choice to reject the diagnosis and consequently to ignore the treatment. Advice and prescriptions given by caregivers, who neglect the patients' own knowledge and past experiences, will often be considered as not worth following. This increases the gap between caregiver and the patient and increases the distrust of health care. A woman describes how she was prescribed medication although she did not believe in the doctors' diagnosis:

I do not have it I said. But then I thought that maybe I should not go to Spain if I have TB, so it's best to keep quiet so I took all the drugs, and then I buried them somewhere around here [pointing out to the yard].

The patient's learning ability is lost when the patient is excluded from communication and decision making regarding their treatment.

\section{The results of learning}

Learning to live with long-term illness gives insight into the importance of allowing the illness more space in one's life. It is an insight that the affected obtain by learning to listen to himself, to his own body. When a person learns to live with a long-term illness this often results in development of maturity and self-awareness enabling an inner calm. Learning is about making the best of the life that the person has.

Long term illness prevent a full life, but a correct diagnosis, that is, a diagnosis that the person trusts, gives incentive to make life changes. Previous high expectations can be adapted to a reasonable level. This means that the illness is allowed more space in their lives, and thus also creates the all-important prerequisite for well-being. Learning is about understanding the significance in taking the time to get to know the stranger. It is easy to regret a detrimental former way of life when it's results becomes noticeable.

When I think of how my body has been damaged, I regret [...]not my life but that I have not taken care of myself properly.

To not give the illness space in one's life gives freedom, but a freedom that is described as 'costly'. When the person has learned to listen to the signals, she often has reached the insight that the learning process has taken far too long, as demonstrated in expressions such as 'understood too late. The consideration of risks for the future are weighed against what is most valued for the moment. These include wishes for a long life and the person choosing to give the illness room in her life.

Learning means to grow and change. It results in feelings of peace and quiet, making it easier to enjoy life despite the illness. The knowledge that one has reached provides the opportunity to take advantage of good times, which is described as a 'mature life', to extend one's perspective, and to preserve healthy relations. In life with longterm illness, achieved knowledge is good for oneself and one's relatives. Learning is about seeing what life has been like, what has changed, and trying to make the best of today and the future. Giving one's illness more space results in personal growth and the opportunity to enjoy more of the life that the person actually has.

\section{Discussion}

There is a significant amount of research about patient education, but considerably less that describes patients' learning and, above all, very little that has a distinct life-world theoretical foundation. Ekebergh [20] maintains that most studies do not reach the core of the complex problems inherent in learning not venturing beyond the how-questions to the what-questions. The aim in the present study, however, has been to describe the meaning of learning to live with a long-term illness in its deepest sense. This means that the aim has been to get answers to the what-questions, that is, what learning entails for persons with long-term illness. The chosen approach [15] and way of studying the phenomenon has contributed to getting answers to both the what-questions and the how-questions and provides important new knowledge.

The study has focused on the learning process dealing mainly with genuine learning, something which I maintain is rare in the present day caregiver patient relation and much differs from the learning of information $[8,21]$. The information society of today makes it easy for patients and relatives themselves to seek and obtain information about illness and treatment. There is nothing that emerges in the results that would indicate a lack of information. Previous research $[7,8,22,23]$ has shown that patients do not lack information about illness and treatment, but that they still have problems in translating this information into their own situation. From the results of the present study, it can be seen that information and teaching on an 'admonishing level', a level where patients are expected to do what they are told, is not the same as a genuine learning.

Genuine learning takes place at a deeper level. Our results have shown that genuine learning has taken place when the sufferers have gone from having ignored their situation of being ill to letting the illness be a part of their lives. This is shown in the results as hard work that takes time. The patient's genuine learning certainly grows gradually into knowledge. The problems are, however, that this extended learning process, in a life with long-term illness, contributes to the advancement of the illness and that complications can occur. In the results, this has been seen to cost the sufferers a great deal. Speeding up the learning process thus has many virtues.

A paradox can be seen in learning how to live with long-term illness. This paradox entails that if the illness is not given space in a person's life, it will intrude and demand much greater space later on. Patients need help to see and understand this paradox. There are ethical problems in patient education that need to be addressed. The questions that can be asked are the following: Do professionals have the right to force new knowledge onto the patient? Has the professions' duty to inform and supervise been correctly formulated? The ethical questions also raise musings about personal responsibility in connection with long-term illness.

What is the actual aim in learning to live with long-term illness, and who sets this aim? Do patients, professionals, and society have the same aim? Is the aim a transmission of information, a change in behaviour and treatment compliance, as previous research has shown? Does the aim concern the sufferers being able to gain insight into their actual situation, accept it, and reconcile to their situation? According to this study, the aim concerns a changed understanding, insight, personal development, and an ability to take charge of one's life with a long-term illness.

\section{Conclusion}

Learning to live with long-term illness is a very complex phenomenon; it is incorporated in life as a whole and is thus difficult to distinguish from living. The learning affects the whole person, the body, cognitive functions, emotions, practical matters, and social life. This complexity has to be understood in order for genuine learning to be possible. 
Citation: Berglund M, Källerwald S (2012) The Movement to a New Understanding: A Life-World-Based Study about How People Learn to Live with Long-Term Illness. J Nurs Care 1:125. doi:10.4172/2167-1168.1000125

Page 5 of 5

The need for learning does not concern learning merely about an illness, it concerns the person's whole health situation.

Learning to live with long-term illness has to be seen as a lifelong quest in the person's life.

The learning process thus contributes to the possibilities for changes and new priorities in life. The result of learning can be understood as a movement to a new understanding demonstrated by the way the person acts and allows the illness more space in her life.

Learning strategies are to be developed to support patients' genuine learning.

\section{Practical Implications}

The new perspective on learning to live with long-term illness, which is presented here, places many demands on care organizations to provide care that is based on the patient's needs and not simply the diagnosis of the illness. In order for patients to be seen and supported as whole and learning individuals, a change of paradigm is needed, one in which professionals see their roles being changed from giving information to providing support for the patients' genuine learning. This study presents a possibility to understand patients' learning processes as well as increasing their health and wellbeing. Learning strategies have to be developed that focuses on the patient's experiences as a starting point and results in a life-world and caring perspective.

\section{References}

1. Thorne SE, Paterson BL (2000) Two decades of insider research: what we know and don't know about chronic illness experience. Annu Rev Nurs Res 18: $3-25$

2. Thorne S, Paterson B, Acorn S, Canam C, Joachim G, et al. (2002) Chronic illness experience: insights from a metastudy. Qual Health Res 12: 437-452.

3. Toombs SK (1993) The Meaning of illness-a phenomenological account of the different perspectives of physician and patient. Kluwer Academic Publisher, Boston.

4. Nordberg L (2008) När kroppen sätter gränser-en studie omatt leva med hjärtsvikt I medelåldern. Växjö University Press.

5. Newman S, Steed L, Mulligan K (2004) Self-management interventions for chronic illness. Lancet 364: 1523-1537.

6. Friberg $\mathrm{F}$, Scherman $\mathrm{MH}$ (2005) Can a teaching and learning perspective deepen understanding of the concept of compliance? A theoretical discussion. Scand J Caring Sci 19: 274-279.

7. Johansson A, Ekebergh M (2006) The meaning of well-being and participation in the process of health and care women's experiences following a myocardial infarction. Int J Qual Stud Health Well-being 1:100-108.

8. Berglund M (2011) Att ta rodret i sitt liv-lärande utmaningar vid långvarig sjukdom. Linnaeus University Dissertations.

9. Ruderfelt D, Axelsson L (2004) Diabetes patient education-factors and interventions of significance for changeing [sic] diet.Vård i Norden [Nordic Journal of Nursing Research \& Clinical]. 24: 9-14.

10. Boardman T, Catley D, Grobe JE, Little TD, Ahluwalia JS (2006) Using motivational interviewing with smokers: do therapist behaviors relate to engagement and therapeutic alliance? J Subst Abuse Treat 31: 329-339.

11. Heidegger M (2008) Being and time. HarperCollins, London.

12. Husserl E (1975) Experience and Judgment. Northwestern University Press, IL. 13. Merleau-Ponty M (2002) Phenomenology of Perception. Routledge, London.

14. Dahlberg K, Dahlberg H, Nyström M (2008) Reflective Lifeworld Research. (2ndedn). Professional Publishing Svc, Berlin.

15. Giorgi A (2009) The descriptive phenomenological method in psychology. A modified Husserlian approach. Duquesne University Press, Pittsburgh.

16. Dahlberg K (2006) The essence of essences - the search for meaning structures in phenomenological analysis of lifeworld phenomena. Int J Qual Stud Health Well-being 1:11-19.

17. The Swedish Research Council (2002) Forskningsetiskaprinciper inom humanistiska-samhällsvetenskaplig forskning. Research Council.

18. World Medical Association (2013) Declaration of Helsinki world medical association declaration of Helsinki.

19. SFS (2003:460).Lagenometikprövningav forskning som avser människor (The law on ethical review of research involving humans).

20. Ekebergh M (2001) Tillägnandet av vårdvetenskaplig kunskap. Reflexionens betydelse för lärandet. Doktorsavhandling. Institutionen för vårdvetenskap, Åbo Akademi, Vasa.

21. Colaizzi PF (1978) Learning an existence. Oxford University Press, New York.

22. Skalla KA, Bakitas M, Furstenberg CT, Ahles T, Henderson JV (2004) Patients' need for information about cancer therapy. Oncol Nurs Forum 31: 313-319.

23. Suhonen R, Nenonen H, Laukka A, Välimäki M (2005) Patients' informational needs and information received do not correspond in hospital. J Clin Nurs 14 1167-1176. 